\title{
Elaboration of a Mechanism for Sustainable Enterprise Development in Innovation Ecosystems
}

\author{
Tatyana Tolstykh ${ }^{1}$, Leyla Gamidullaeva ${ }^{2, *(1)}$ and Nadezhda Shmeleva ${ }^{3}$ \\ 1 Department of Industrial Management, National University of Science \& Technology (MISIS), \\ 119049 Moscow, Russia; tolstyh.to@misis.ru \\ 2 Department of Management and Economic Security, Penza State University, 440026 Penza, Russia \\ 3 Department of Economics, National University of Science \& Technology (MISIS), 119049 Moscow, Russia; \\ nshmeleva@misis.ru \\ * Correspondence: kaf_eop@rambler.ru
}

Received: 31 August 2020; Accepted: 22 September 2020; Published: 25 September 2020

\begin{abstract}
This paper highlights a sustainability and self-organization perspective of the innovation ecosystems. Such issues as under what conditions self-organization takes place and what mechanisms form an innovation ecosystem in a sustainable way are underexplored in the academic literature. To ensure self-development of actors in the ecosystem, a self-adjustment mechanism is needed that allows implementation of sustainability principles. This article proposes a practical tool for assessing an actor in an ecosystem using the method of analytic hierarchy process (AHP), developed by T. Saaty. It allows for operationalizing the processes of self-organization in the ecosystem without an external intervention and addresses the main implications for sustainable development of innovation industrial ecosystems. The authors illustrate their assumptions with an empirical case study of the industrial ecosystem "Technologies for Improving the Quality of Life" (Moscow, Russia). The propositions arising from this analysis provide information to help academics, policymakers, government, and individual enterprises with a more adequate understanding of the practical mechanisms and tools that help trigger self-organization and sustainable development of the innovation ecosystems.
\end{abstract}

Keywords: innovation ecosystem; industrial ecosystem; sustainability; self-organization; analytic hierarchy process (AHP); cross-validation

\section{Introduction}

The Sustainable Development Goals (SDGs) aim to promote sustainable economic growth through higher levels of productivity and implementation of technological innovations. As stated in Goal 9, there is a request to build "sustainable infrastructure, promoting sustainable industrialization and innovation" [1].

There is a need for an integrated multi-stakeholder approach to progress across the multiple SDGs set in the 2030 Agenda for Sustainable Development. Moreover, new organizational models to foster sustainable innovative development are required.

Technological, digital, environmental, and political trends swiftly and universally have covered all social and economic processes. Emerging fundamental challenges change approaches to the development of socioeconomic systems towards:

(1) Changing the paradigm from "human for economics" to "economics for human";

(2) Transformation of the environment through the triad of nature, technology, and culture;

(3) Transformation of the new world order as a result of the humanitarian and technological revolution. 
Market participants are forced not only to respond to challenges, but also to predict them. This requires a search for new behavioral models and new approaches to strategizing.

This situation is especially relevant for industrial enterprises, which have a significant inertial log within their industry specifics.

Industrial enterprises have always played the role of the country's economy driver. However, to ensure sustainable development, maintain their competitive advantages, adapt to the requirements of the realities of an individual enterprise flexibly and instantly is becoming increasingly difficult. It is practically impossible to reflect new challenges alone for small enterprises or those already in the stagnation stage.

The most acknowledged definition of "sustainable development" is that proposed by the United Nations World Commission on Environment and Development (UNWCED): "Sustainable development is development that meets the needs of the present without compromising the ability of future generations to meet their own needs" [2]. This means that the strategy of each market participant focused on long-term development should ensure a balanced triad of economic, social, and environmental components.

There are different approaches to the concept of sustainable enterprise development [3-9]. Sustainable enterprises take into account both the economic and social aspirations of people related to the enterprise and the impact on the natural environment [7]. The main positions of modern researchers tend to comply with:

(1) Principles of social responsibility to employees and society;

(2) Balance of economic and environmental indicators;

(3) Integrity of the natural ecosystem through reimbursement of environmental expenses and assessment of the impact of enterprise on the state of the environment;

(4) Provision of innovation and project orientation.

The importance of the social aspect in the enterprise development strategy has been especially aggravated by the pandemic situation, which forces many companies to rebuild their target development vectors taking into account the safety of both their employees and employees of partners and customers.

Summarizing the positions of researchers, the authors understand the sustainable development of an individual industrial enterprise as the long-term balanced development of a company, the targets of which are accumulated and harmonized according to the principle of triad: technological, social, and environmental areas (Figure 1).

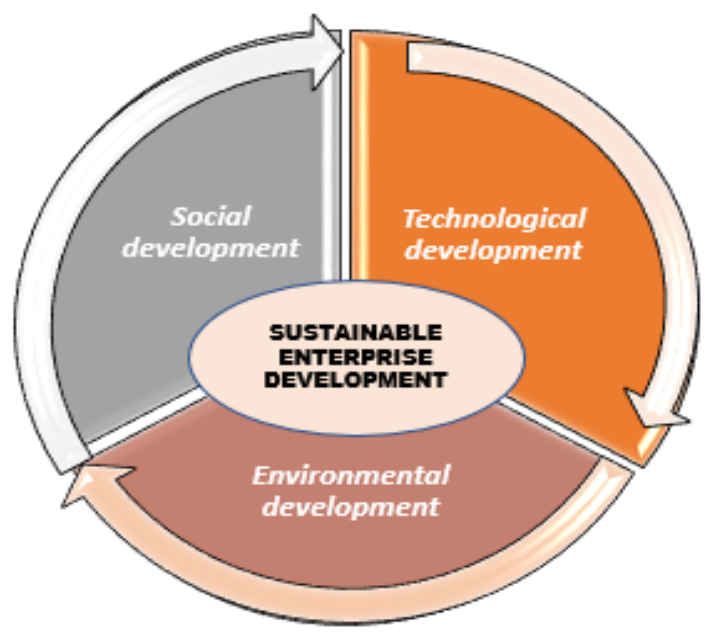

Figure 1. The triad of sustainable enterprise development.

In the digital age, a large role is given to innovativeness in the triad of sustainable enterprise development. 
Innovative sustainable development is the development in which favorable conditions are created (organizational and economic mechanisms, scientific and technical base, motivational and stimulating mechanisms) for generation and implementation of innovative activities, introduction of scientific and technological developments in production, and promotion of high-technology products on the market. The search for organizational and managerial models that provide innovative sustainable development through synergistic symbiosis has been going on for several decades. These models include clusters, industrial networks, and industrial and eco-industrial parks. Each of these models has its own advantages and limitations. The main limiting point of network and cluster models is that horizontal synergistic interaction between participants is subject to vertical management from above. The management system can be either a state structure or a large enterprise, building network relations with other enterprises for their interests. Elements of the management vertical initially violate the principles of harmonization and balanced development of individual participants, since the interests and priorities of the governing body do not always coincide with the interests of other participants. In Antifragility: Things That Gain from Disorder, Nassim Nicholas Taleb [10] defined large vertical systems as "fragile" in terms of the risks of making managerial decisions. In contrast to such systems, the combination of companies on partnership terms without vertical administration is "anti-fragile" with respect to internal and external challenges. That is why another model of enterprise interaction, being the innovation ecosystem, has been actively studied and discussed in the scientific community in the last few years. The ecosystem model allows for forming a special friendly environment from enterprises through a voluntary partnership for the generation and implementation of innovative projects in various fields. It gives an opportunity for the ecosystem participants to be open to external challenges through the integration of resources, knowledge, information, technologies, competencies, ensuring the principles of their sustainable development. This approach allows for developing the open innovation perspective through the principles of ecosystem, when all participating companies, regardless of their size and type of activity, benefit from networking and collaboration.

Despite the increased interest of the scientific community in the problem of the formation and development of innovation ecosystems, one should admit the weak methodological elaboration of this theory, which complicates its application in practice.

The article is organized as follows. Section 2 provides a theoretical overview of an innovation ecosystem and discusses the previous works, which have utilized the analytic hierarchy process (AHP) approach to justify the selection of this tool for our methodology. Section 3 is devoted to theoretical foundations of our research introducing the authors' conceptual assumptions and chosen approaches. Section 4 presents a new methodology for the evaluation of an ecosystem's actor using the AHP method. Evaluation of the ecosystem's actor is carried out on the basis of blocks of indicators, including ecological dimension. Section 5 focuses on the implementation of the proposed methodological approach. The authors illustrate their assumptions with an empirical case study of the ecosystem "Technologies for Improving the Quality of Life" (Moscow, Russia). In Section 6, the authors discuss propositions arising from the conducted analysis to bring out the self-organization features of innovation ecosystems and their implications in terms of sustainability development. Additionally, some limitations of the research and future research perspectives are proposed.

Finally, Section 7 highlights the key findings of the study and presents the theoretical contribution and practical significance of the study.

\section{Literature Review}

Innovation is considered to be a crucial factor, which can improve the competitiveness of firms and ensure sustainability. Collaborations have become a trend in regard to enabling long-term business growth. Open innovation combines internal and external resources to generate new technologies and identify new paths to the market [11]. Meanwhile, the issue of sustainability has become critical in recent years. Traditionally, the term "sustainability" is articulated as the three-dimensional framework—economic, social, and environmental (Figure 1). 
In the current era of active creation of collaborations and alliances, rapid development of open innovations has started to affect enterprises and the whole ecosystem. Entrepreneurial sustainability is relying more and more on collaboration through dynamic and open platforms. These trends bring new topics to the concept of sustainability in terms of culture creation [12], governing mechanisms [13], communication channels, and other aspects of open innovation dynamics [14].

With the development of the concept of "open innovation," the management of companies is increasingly focused on results, regardless of the place of their creation and the origin of the resources involved. Within the paradigm of open innovation, large companies dominate, forming innovative markets and networks. Small and medium-sized companies, including start-ups, have more limited financial and human resources, are focused on a shorter time horizon, and experience difficulties in implementing innovative strategies. Such enterprises are faced with the need to either allocate significant costs for attracting highly qualified personnel, initiating and implementing projects, or dependence on external sources of information, knowledge, competencies, and technologies $[15,16]$.

Members of the ecosystem include suppliers, producers, competitors, and other stakeholders (educational and research institutions, communities, public sector actors, etc.). In this regard, the question of innovation in sustainable development needs to be analyzed at the level of the whole value chain, not just the firm. Thus, the study of the problem of sustainable enterprise development is possible through an ecosystem approach. Acting at the level of the ecosystem is often necessary to investigate complex interactions and self-organization mechanisms taking place between all stakeholders.

Alongside open innovation is the quadruple-helix theory [17], which identifies relations between various stakeholders (civil society, media, and the culture-based public) and integrates top-down policies and grassroots innovations.

The quintuple-helix model [18] expands the previous research by highlighting the role of the environment and thus brings together the concepts of innovation ecosystem and sustainable development.

The concept of an ecosystem is associated with a natural ecosystem in which living organisms and their habitats are united, harmonious, and balanced [19].

In a number of publications, an ecosystem is understood as a continuation of the development of cluster models. For example, Jacobides, Cennamo, and Gawer [20] believe that an innovation ecosystem refers to various organizational forms of economic activity, interconnected by specific types of complementarity. Such a definition, in fact, is an analogue of cluster industrial symbioses and does not reflect a fundamental difference from them. Moore [21] suggests another definition of ecosystems. Here, ecosystems are understood as an economic community supported by a basis of interacting economic units that are the organisms of the entrepreneurial world, which also does not clarify the goals and principles of their formation. Adner and Kapura [22] and Autio and Thomas [23] consider an ecosystem as a network of interconnected organizations connected around a coordinating firm or platform, which again is similar to network models and contradicts the principle of self-organization, being the basis of the analogy of natural and socioeconomic ecosystems. The definitions formulated by Kleiner [24] and Proskurnin [25] are more logical from the standpoint of the principles of consistency, balance, and self-organization. Proskurnin [25] believes that an innovation ecosystem is a self-organizing, self-regulating, and self-developing open system, characterized by input flows of ideas, value, people, information, and resources.

The most comprehensive definition of innovation ecosystem was developed by Granstrand and Holgersson [26]. According to the authors, such an ecosystem is "the evolving set of actors, activities, and artifacts, and the institutions and relations, including complementary and substitute relations, that are important for the innovative performance of an actor or a population of actors" [26]. Thus, the authors put focus on the intertwined CS-relations (competition/substitution), providing additional precision and a balanced view of what is going on in an innovation ecosystem [27].

Generally, there have been formed five theoretical directions on innovation ecosystems (Figure 2) [28-36]. 


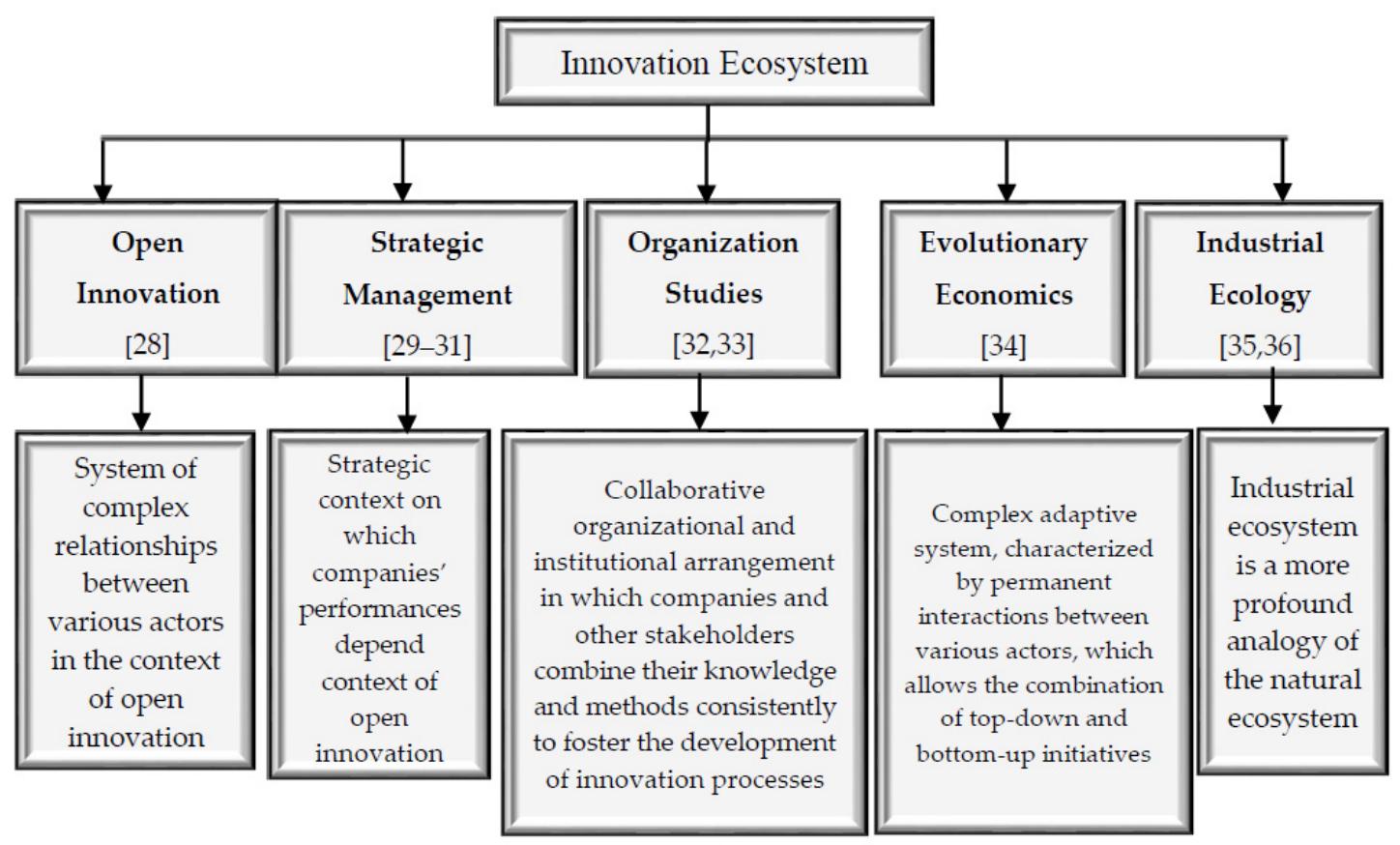

Figure 2. Main theoretical directions within the innovation ecosystem concept $[26,27]$.

Our research interest lies primarily with the fourth and fifth research directions. From an evolutionary economics perspective, actors' self-organization and self-development is critically important. The industrial ecology approach relies on the assumption of an industrial system that develops by optimizing the production of goods and materials minimizing industry's impact on the environment through circular processes. Within self-organization, different actors develop innovation processes to recycle products, reduce industrial, natural resources, and energy waste, exploit local resources, etc. The CS (competition/substitution) relations are sources of sustainability of this industrial system. The ecological dimension refers to sustainability through self-organization [26].

Having agreed with the above researchers on a number of points, the authors of this study consider an industrial innovation ecosystem as a self-organizing and self-developing system without an external governing body, creating a special business-friendly environment for generating and implementing innovative projects on the basis of competition/substitution relations leading to sustainability [37].

It should be understood that the implementation of the ecosystem model requires coordination systems and mechanisms of actors' interaction, different from traditional models, aimed at stimulating sustainable development of enterprises. In practice, as a rule, the roles of actors are not clearly defined and may change as the ecosystem develops. The role of the core company in coordinating the ecosystem has been discussed in detail [37]. According to the authors [38], transparent and clear rules for cooperation and interaction of actors are primarily required for the development of an ecosystem.

Any ecosystem should be open to new participants to be developed. Some ecosystems are evolving towards a more market-based logic, encouraging competition and independence of suppliers and partners. In these ecosystems, complementors become more versatile and less valuable to the core company. Other ecosystems can gradually transform into hierarchical supplier-based value chains, where the network architect clearly defines the rules of the game and regulates the relationships between the participants [20].

In our opinion, the nature of an innovation ecosystem, as an analogue of a natural one, is that the vertical hierarchy of administration is completely absent in this model. First of all, this concerns the process of assessing and selecting new actors to participate in ecosystem projects, which should be as objective and independent as possible. In addition, in the context of our research, the key question is how to stimulate enterprises in innovation ecosystems to develop sustainably with limited resource potential, a shortage of qualified personnel, and professional knowledge. 
Despite numerous research studies on entrepreneurial sustainable development, understanding how sustainability management models operate remains a great challenge. Thus, there is a relevant gap between the theoretical development of sustainability models and practical application of these models [39-42].

Many current works are devoted to the investigation of the initial barriers that negatively impact on the adoption of sustainable practices [43-45]. In [43], the authors highlighted the internal forces stimulating enterprises to introduce innovative sustainable management tools. They revealed that capability of the enterprise to engage with its stakeholders, as well as some adequate managerial and organizational features, are the main drivers for implementing sustainable development practices.

In this regard, the dynamic capabilities approach creates a logical foundation while considering sustainable development in the context of innovation [46]. Integrated with sustainable development issues, the notion of dynamic capability sheds light on the way the enterprises manage to perceive sustainable development issues by building an innovation dynamic.

Several recent studies explore the concept of dynamic capabilities in relation to corporate sustainability issues $[47,48]$.

Thus, incorporating sustainability efforts into the business practices of the organization is one of the key barriers for the entrepreneurs' sustainable development.

To solve the above problems, new tools and mechanisms for the introduction of actors' self-organization in the innovation ecosystem, stimulating their sustainable development, are needed. This issue has received very little attention in the scientific literature.

The authors, therefore, position the consideration on innovation ecosystems in self-organization and sustainability perspective. The main research question is how to operationalize the processes of self-organization in the innovation ecosystem without an external governing body. To this end, the authors propose a new tool for cross-validation of ecosystem actors based on the method of analytic hierarchy process (AHP) [49-51], which will ensure the independence and transparency of the process of assessing actors for the suitability of an enterprise to a particular role in the initiated project, taking into account the principles of ecosystem interaction and sustainability.

The method of analytic hierarchy process is relevant in group decision-making and is aimed at solving practice-oriented tasks of multicriteria optimization. The ability of taking into account a large number of both quantitative and qualitative criteria for optimality are among the main advantages of this method. The simplicity and versatility of its use formed the basis for mass application in solving tasks of the optimal allocation of resources according to established priorities among many alternatives. The AHP allows to evaluate alternatives based on the calculation of priorities (relative importance) using the pairwise comparison procedure. The advantage of the method is the ability to reasonably compare heterogeneous factors. The AHP is widely used in practice and is actively developed by scientists around the world, for example, for risk evaluation [52-54], for evaluation of sustainable development of territories, cities, and industry [55-58]. The method has also found wide application in solving problems of analysis and evaluation of relationships in biological ecosystems [59-61].

Thus, in this article, the authors propose to use the analytical hierarchy method as a tool for self-tuning the ecosystem, namely, for actors' cross-validation with each other. Ultimately, this will make it possible to operationalize the processes of self-organization in the ecosystem and will contribute to its sustainable development of industrial enterprises as ecosystem's actors.

\section{Conceptual Framework}

The Davos Manifesto, issued for the World Economic Forum in 2019, initiated by Klaus Schwab [62], speaks of a new model of capitalism—stakeholder capitalism, where companies should stand up for competitive equality in the "game field," especially in the "economy of Internet platform," and this very idea is the basis for the formation of an innovation industrial ecosystem.

The nature of the industrial ecosystem, as an analogue of the natural one, is the absence of vertical hierarchy of administration therein. The association of participants (actors) is self-organizing on the 
basis of voluntariness, equality, and partnership, which does not imply randomness and spontaneity. The unifying principle in the ecosystem is the presence of an intellectual core or a mastermind, being a certain idea that inspires and unites actors among themselves. A new technology, a project, or a platform could become such an idea. For example, in accordance with the UN sustainable development goals and the Davos Manifesto of 2019, the development of new technologies or materials to improve the quality of life could be such a mastermind. An introduction of such a model will result in creating an intellectual environment for the implementation of breakthrough technological projects on the principles of network partnership, cross-border and cognition. Such a model helps participants to achieve their own interests, goals, and competitive advantages through the development and implementation of new products, technologies, materials, engineering, and digital transformation of business processes, including recycling (Figure 3).

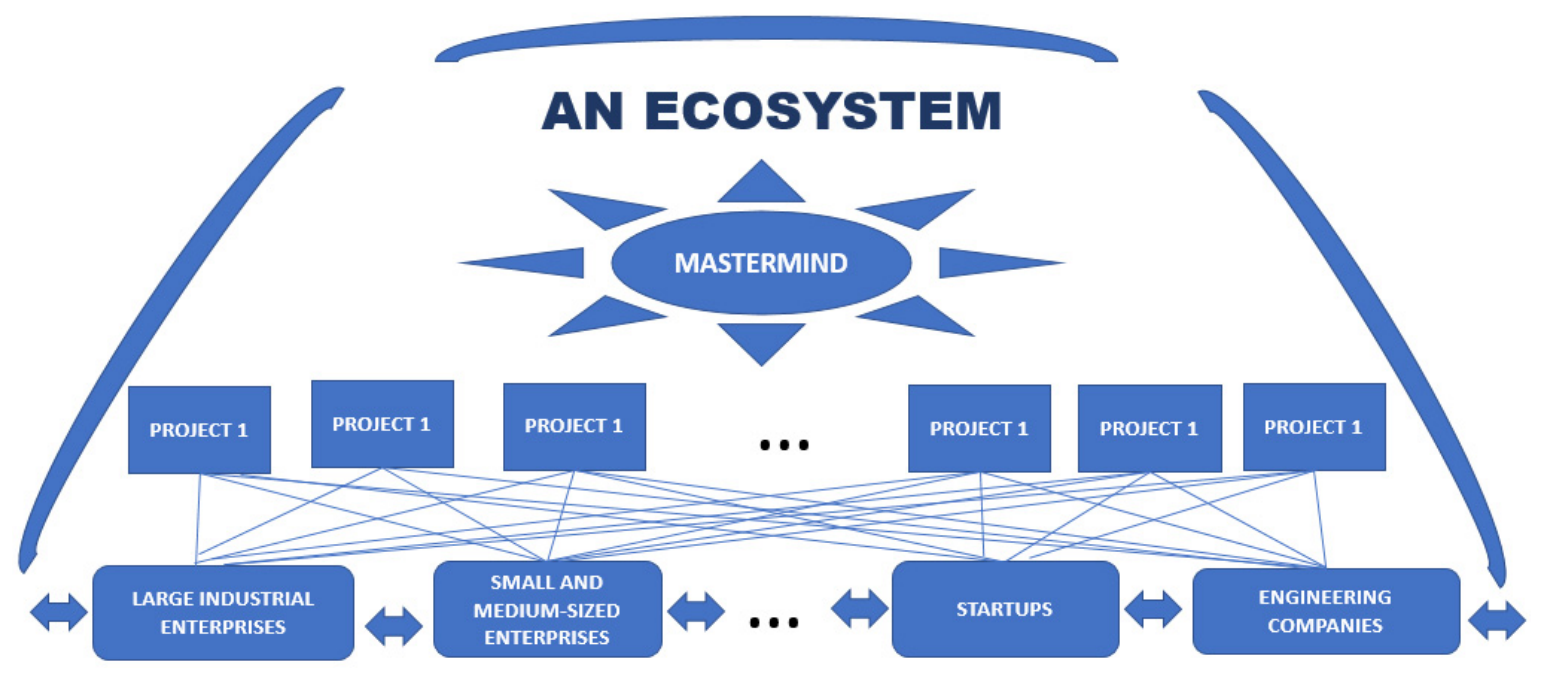

Figure 3. An ecosystem structure. Source: Own elaboration.

Industrial and engineering enterprises, research and scientific organizations, startups, investment funds, industry and territorial authorities, that is, any organizations interested in the innovative development of both their enterprise and the industry as a whole, can be participants or actors in such an ecosystem.

The sustainability of an industrial innovation ecosystem can be defined as the ability to do the following:

$\boldsymbol{V}$ constant exchange of information, knowledge, technologies between actors;

$\checkmark$ generation of ideas;

$\checkmark$ environment that ensures the development and implementation of innovative projects;

$\checkmark$ ensuring the sustainable development of actors.

The principles of combining actors into an ecosystem can be grouped into two levels:

(1) Principles of direct ecosystem interaction:

(a) Self-organization and self-development;

(b) Trust and partnership;

(c) Corporate culture;

(d) Customer focus;

(e) Project orientation, innovativeness and openness to change;

(f) Collaboration via information and intellectual resources;

(g) Interdisciplinarity;

(h) Ensuring information and economic security. 
(2) Principles of sustainable development of actors:

(i) Quality-of-life project orientation;

(j) Observance of environmental safety by actors;

(k) Focus of actors on resource conservation;

(l) Financial stability of actors;

(m) Market stability of actors;

(n) Operational stability of actors.

Within the ecosystem, lots of projects can be implemented simultaneously, and each actor of the ecosystem has the opportunity to perform various roles and participate in different projects at the same time. Table 1 presents possible roles of actors in the projects [27].

Table 1. Roles of actors in the ecosystem.

\begin{tabular}{|c|c|c|}
\hline Ecosystem Roles & $\begin{array}{l}\text { Tasks and Functions in the } \\
\text { Ecosystem }\end{array}$ & Potential Actors \\
\hline Initiator, customer & $\begin{array}{l}\text { Initiation of a new project. Project } \\
\text { testing and implementation }\end{array}$ & Industrial enterprises \\
\hline Integrator & $\begin{array}{l}\text { Accumulation and generation of } \\
\text { domestic and world experience in } \\
\text { industries, ensuring coherence of } \\
\text { interactions in the ecosystem, } \\
\text { balancing energy exchange and } \\
\text { resources between actors }\end{array}$ & $\begin{array}{l}\text { Universities, research } \\
\text { organizations, project offices, } \\
\text { digital platforms }\end{array}$ \\
\hline Developer & $\begin{array}{l}\text { Design, logical and technological } \\
\text { development, formalization of } \\
\text { ideas. Generating ideas and } \\
\text { initiating projects with other } \\
\text { actors. Project testing and } \\
\text { implementation }\end{array}$ & $\begin{array}{l}\text { Technoparks, startups, } \\
\text { engineering companies, research } \\
\text { structures, universities. }\end{array}$ \\
\hline Investment resource provider & Project financing & $\begin{array}{l}\text { Investment and venture funds, } \\
\text { sectoral and territorial authorities }\end{array}$ \\
\hline Unique resource provider & $\begin{array}{l}\text { Providing access to unique } \\
\text { technologies, materials, } \\
\text { competencies, and information }\end{array}$ & $\begin{array}{l}\text { Technoparks, startups, } \\
\text { engineering companies, research } \\
\text { structures }\end{array}$ \\
\hline Project promoter & $\begin{array}{l}\text { Promotion of implemented } \\
\text { projects, conversion of past } \\
\text { projects experience into new } \\
\text { projects. Project commercialization }\end{array}$ & Any ecosystem actor \\
\hline Circularity generator & $\begin{array}{l}\text { Providing possible long-term } \\
\text { resource usage with the ability to } \\
\text { regenerate project outputs into } \\
\text { other projects }\end{array}$ & Any ecosystem actor \\
\hline
\end{tabular}

The main difficulty in the formation of ecosystems is operationalization of such basic ecosystem principles as self-organization and self-development. The authors have proposed a mechanism for implementing these principles through cross-validation as a new self-adjusting loop within the ecosystem.

The first management model is the simplest traditional one, implemented as a response of the system to external or internal challenges. The limitation of such management model is that the challenge has already occurred, the problem has happened, and the problem-solving policy always loses to the policy of preventive measures.

One of the basic laws of the development of organizational and economic systems, namely, the law of self-preservation, states that the sum of the system potentials should exceed the sum of the external 
and internal challenges. That is, for effective and sustainable development, the system is to constantly monitor the emergence of new information, tracking all kinds of trends, and, based on the knowledge gained, increase its potential via a self-adjusting loop. Therefore, via realizing the self-adjusting loop, the second management model allows the system to be resistant to external and internal challenges, preventing or minimizing them via preventive measures, through a constant increase in its potential.

These two loops complement each other and work effectively within the same enterprise, providing it with sustainable development in accordance with the laws of the organization.

Sustainable development of actors within the ecosystem is possible only when there is also a mechanism that allows actors to effectively interact within the ecosystem, flexibly respond to challenges, get ahead of negative phenomena, and adjust their development strategies. The third management model, shown in Figure 4, implements a management system based on the principle of self-organization, where each actor monitors both their own potential and the potentials of actors and projects implemented within the ecosystem.

Figure 4 presents three different types of management models.

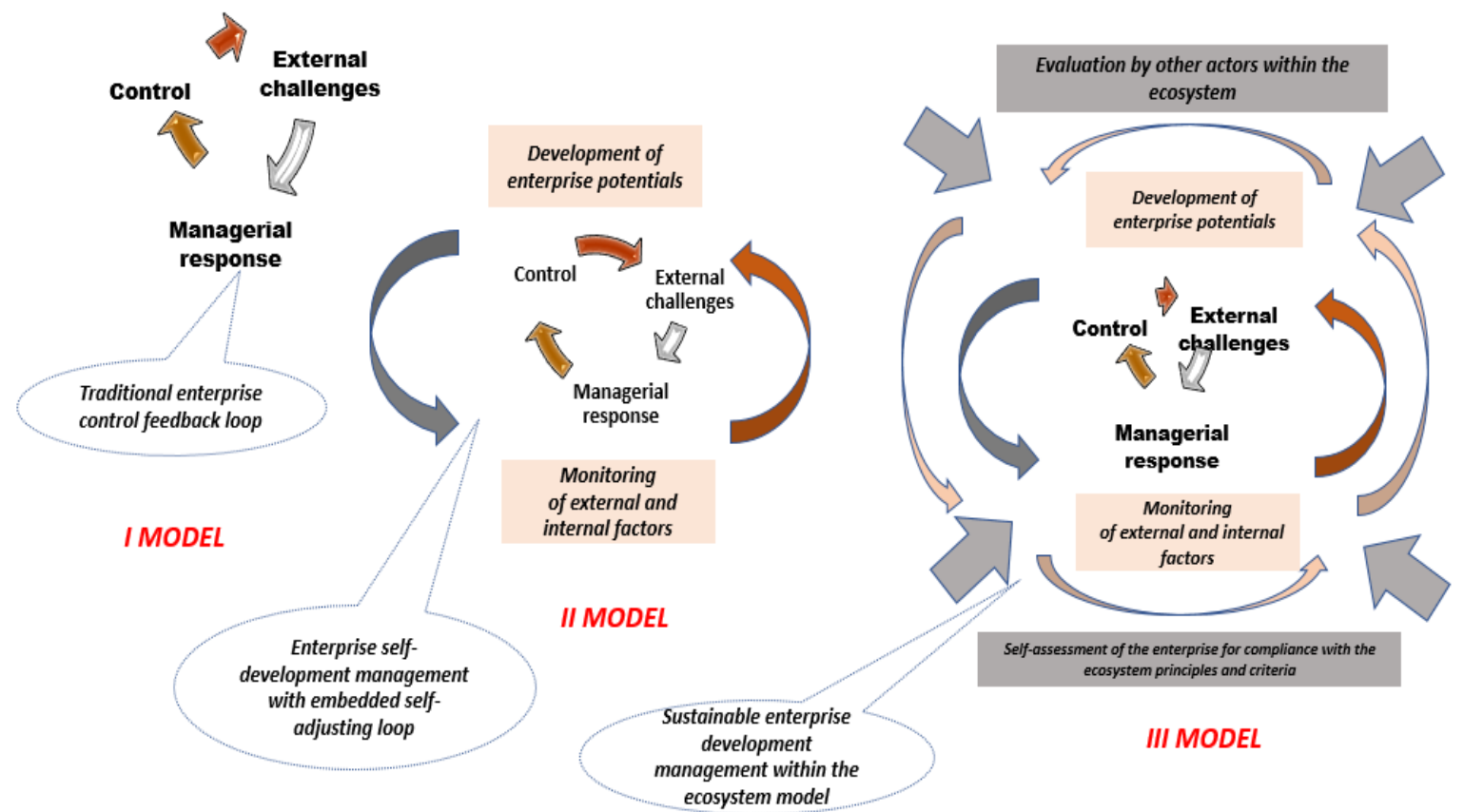

Figure 4. Classification of management models. Source: Own elaboration.

Such a self-adjusting mechanism stimulates actors to be attractive to other participants in the ecosystem, independently implementing an internal policy of corrective actions, building their own vector of goals in accordance with the principles of ecosystem formation. Since there is no vertical control that defines the structure and place of each actor in the system from above, the main mechanism for the ecosystem formation and the distribution of roles therein is the desire of a particular actor and its usefulness to other participants. The basis for building a self-adjusting mechanism in the ecosystem should be an ecosystem platform created by cross-validation of actors with each other.

The evaluation is proposed to be carried out in several stages.

The first stage is to enter the ecosystem. At this stage, the enterprise can independently evaluate its resource potential and its development strategies for compliance with the principles of the ecosystem. The enterprise should conduct such evaluation regularly in the framework of the self-adjusting loop of the second management model shown in Figure 4.

At the next stage, evaluation is carried out by other actors for compliance with the enterprise being evaluated for one or another role in the initiated project. 
Finally, at the third stage, evaluation is carried out after the project has been implemented for compliance with the effectiveness of the enterprise role in the project.

Having accumulated positive points by cross-validation, the actor becomes attractive in terms of cooperation in joint projects for other participants. The results of evaluating the activities of the actor by other project participants will enable the enterprise to focus on its problem areas, to pursue a policy of internal corrective measures, while ensuring the sustainability of its development.

On the other hand, the ecosystem platform will allow each actor to constantly monitor the activities of other actors, making an independent decision on cooperation with them in each individual project.

The cross-validation mechanism will further ensure the formation of a unified ecosystem data bank with the goal of creating a project office based on blockchain principles.

\section{Research Methodology}

The authors propose using the analytic hierarchy method as a tool for ecosystem self-adjusting through the cross-validation of actors within an ecosystem.

In accordance with the theory of decision-making, the choice of a business partner (actor) refers to the types of tasks that are called partially structured. Modeling of such tasks at a quantitative level is practically impossible, since not all connections between system components can be quantitatively taken into account due to the lack of the required amount of information. In this case, the required connections are usually established by experts. In this case, decision-making comes down to choosing one of the synthesized alternatives. However, a characteristic feature of multicriteria tasks is that there is no alternative that would have the best values for all criteria.

The method of analytic hierarchy process is a mathematical tool for a systematic approach to solving decision-making problems. While engaging in decision-making and predicting possible results, managers usually face a complex system of interdependent components (resources, goals, company personnel, etc.) that needs to be analyzed.

The AHP approach consists in decomposing the problem into simpler components and stage-by-stage prioritization of the estimated components using pairwise comparisons. At the first stage, the most important elements of the problem are identified. The second stage is devoted to the search of ways to verify observations, test, and evaluate elements. At the third stage, the development of a problem-solving method and assessment of its quality is carried out. The whole process is tested until it is certain that the process has captured all the important characteristics necessary to present and solve the problem.

The process can be carried out over a sequence of hierarchies. In this case, the results obtained in one of them are used as input data when studying the next one. The hierarchical structures used in the AHP are a tool for high-quality modeling of complex problems. The top of the hierarchy is the main goal. The elements of the lower level represent many options for achieving the goal (alternatives). Intermediate items correspond to criteria or factors that link the goal to the alternatives. The sequential implementation of all the steps of the AHP provides for the possibility of changing the structure of the hierarchy, in order to include in it newly emerging, or previously not considered important, criteria and alternatives.

That is why the AHP is used by the authors as a cross-validation tool for an ecosystem's actors. At each stage of the assessment, the composition of the actors, the criteria, and the assessment procedure itself can change.

Here are some of the AHP applications:

a. Choice is the selection of one alternative from a set of alternatives;

b. Prioritization/evaluation is determining the relative merit of a set of alternatives;

c. Resource allocation is finding the best combination of alternatives subject to a variety of constraints;

d. Benchmarking of processes or systems with known processes or systems;

e. Risk management. 
The authors propose using the hierarchy method as a tool for ecosystem self-adjusting, namely, for cross-validation of actors by each other (Figure 5).

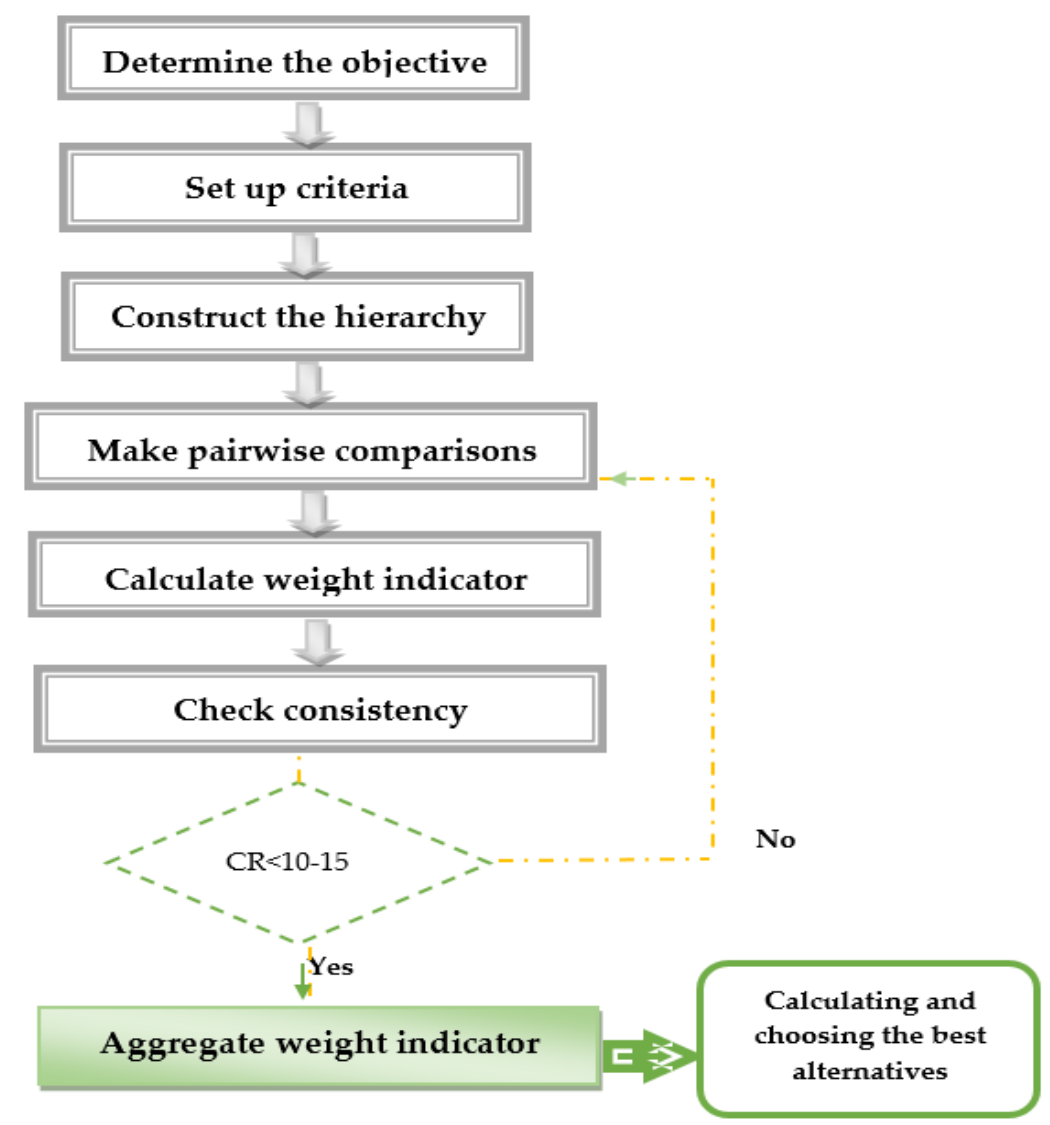

Figure 5. A flowchart for the APH methodology. Source: Own elaboration.

The first AHP step is to construct a hierarchical structure combining the goal, criteria, and alternatives that influence the choice of decision.

The goal is to evaluate the potential and sustainable development of the enterprise (company) by ecosystem actors for compliance with a particular role in the project being initiated. The indicators are divided into five groups (blocks). Three blocks of indicators are formed, taking into account the principles of sustainable development of actors. The list of quality indicators is taken as the basis used to compile the ESG (Environmental, social and governance) criteria rating of companies [63]. Compliance with the ESG principles implies the introduction of the best practices in the strategy and business companies in such areas as the ecology (Environment), social policy (Social) and management (Governance). The ideological basis of these practices is based on the UN Sustainable Development Goals (SDGs).

Besides, two blocks of indicators have been identified for assessing the potential of companies in terms of their usefulness to the ecosystem (Table 2). The types of potentials depend primarily on the type of ecosystem being analyzed. The article concerns innovation industrial ecosystems. Accordingly, innovative and technological potentials are evaluated. The list of indicators for assessing potentials is based on the HSE University (Higher School of Economics) data books data [64]. 
Table 2. Indicators for evaluating a company as a potential actor in the ecosystem.

\begin{tabular}{|c|c|c|}
\hline No. & $\begin{array}{l}\text { Integrated } \\
\text { Indicator }\end{array}$ & Criteria \\
\hline 1 & $\begin{array}{c}\text { Technological } \\
\text { potential }(T)\end{array}$ & $\begin{array}{l}\text { Technological processes efficiency level } \\
\text { Resource intensity of production } \\
\text { Product quality } \\
\text { Level of automation and digitalization of production } \\
\text { Share of unique technologies in the overall structure }\end{array}$ \\
\hline 2 & $\begin{array}{l}\text { Environmental } \\
\text { friendliness }(E)\end{array}$ & $\begin{array}{l}\text { Level of implementation of modern resource-saving "smart" technologies } \\
\text { Amount of financing of environmental protection } \\
\text { Amount of industrial and solid waste } \\
\text { Level of water, air, and soil pollution } \\
\text { Availability of educational environmental programs and projects }\end{array}$ \\
\hline 3 & $\begin{array}{c}\text { Social } \\
\text { environment }(S)\end{array}$ & $\begin{array}{l}\text { Level of social spending and investment in human capital } \\
\text { The number of accidents in the company per } 1000 \text { employees } \\
\text { Degree of employee satisfaction with environmental quality } \\
\text { Corporate culture level } \\
\text { Long-term relationships with partners and consumers }\end{array}$ \\
\hline 4 & $\begin{array}{l}\text { Innovation } \\
\text { potential }(I)\end{array}$ & $\begin{array}{l}\text { Innovativeness level } \\
\text { Investment resource endowment for financing innovative programs and projects } \\
\text { Level of personnel qualification and intellectual potential } \\
\text { Viability of innovations } \\
\text { Innovative competence }\end{array}$ \\
\hline 5 & $\begin{array}{l}\text { Management } \\
\text { maturity }(M)\end{array}$ & $\begin{array}{l}\text { Level of infrastructure development } \\
\text { Business reputation } \\
\text { Resource provision } \\
\text { Balancing the exchange of knowledge and resources between actors } \\
\text { Level of self-organization }\end{array}$ \\
\hline
\end{tabular}

The proposed scorecard contains a fairly large number of indicators, the significance of which is unequal for various actors of the ecosystem. Therefore, when evaluating potential participants, it is proposed to determine criteria weight coefficients for each actor, which in the future will make it possible to obtain integral estimates.

The second AHP step. A pairwise comparison of criteria importance, is carried out on a nine-point scale:

- Equal importance-1;

- Moderate importance-3;

- $\quad$ Strong importance-5;

- Very strong importance-7;

- Extreme importance-9;

- In intermediate cases, even estimates of 2, 4, 6, 8 are possible.

The ecosystem actors act as experts.

The third AHP step. The normalized priority vector (NVP) is determined:

(a) the geometric mean values is calculated in each row of the matrix:

$$
a_{i}=\sqrt[n]{\prod_{j=1}^{n} a_{i j}}, i=1,2, \ldots, n
$$

(b) the sum of geometric mean is calculated:

$$
S=\sum_{i=1}^{n} a_{i}
$$


(c) NVP components are calculated:

$$
N V P_{i}=\frac{a_{i}}{S}, i=1,2, \ldots, n
$$

The sum of the components of the normalized priority vector is always equal to one. Each NVP component is an assessment of the corresponding criterion importance.

The fourth AHP step. The consistency of the matrix estimates is checked. For this, three characteristics are calculated:

(a) the largest eigenvalue of the matrix:

$$
\lambda_{\max }=\sum_{i=1}^{n}\left(N V P_{i} \times \sum_{j=1}^{n} a_{j i}\right)
$$

(b) the consistency index:

$$
C I=\frac{\lambda_{\max }-n}{n-1}
$$

(c) the consistency ratio:

$$
C R=\frac{C I}{R C}
$$

where RC is the random index, determined theoretically for the case when the estimates are presented in the matrix randomly, being dependent only on the size of the matrix (Table 3).

Table 3. RC values.

\begin{tabular}{ccccccccccc}
\hline Size of the Matrix & $\mathbf{1}$ & $\mathbf{2}$ & $\mathbf{3}$ & $\mathbf{4}$ & $\mathbf{5}$ & $\mathbf{6}$ & $\mathbf{7}$ & $\mathbf{8}$ & $\mathbf{9}$ & $\mathbf{1 0}$ \\
\hline RC & 0 & 0 & 0.58 & 0.90 & 1.12 & 1.24 & 1.32 & 1.41 & 1.45 & 1.49 \\
\hline
\end{tabular}

Matrix estimates are considered consistent, if $C R \leq 10-15 \%$; otherwise, they must be reviewed. If the estimates in the matrix are consistent, then the resulting vector of priorities can be used as importance weights of each block during the selection procedure.

A similar comparison procedure is carried out for each group of criteria within the balanced scorecard (BSC) blocks for each of the potential actors. The final procedure for calculating criteria priorities is carried out by multiplying the criteria priorities by the priorities of the corresponding blocks.

The procedure for evaluating potential actors will be as follows. Based on expert evaluations on a unified scale, participants are given points for each of the listed criteria. The participant's final score is calculated using the additive convolution, which has the following form:

$$
C(x)=\sum_{i=1}^{n} a_{i} C_{i}(x)
$$

where $\mathrm{C}(x)$ is general criterion for an alternative $x$, showing its suitability for achieving the goal; $\left\{C_{j}(x)\right\}_{1}^{n}$ is a set of initial criteria; $n$ is the number of initial criteria; $a_{j}$ is particular criteria priority $C_{j}$.

The higher the integral rating of the actor, the more it is suitable for the intended role.

Consider an example of using the analytic hierarchy process (AHP) method to assess the company for compliance with the role of "Developer" in the ecosystem.

\section{Case: An Assessment of Applicants for the Role of Actors in the Industrial Ecosystem "Technologies for Improving the Quality of Life"}

The method of analytic hierarchy process (AHP) described in the methodological part of the article is implemented on the example of the ecosystem "Technologies for Improving the Quality of 
Life." This ecosystem is of interest for assessing the ecosystem attractiveness and sustainability of actors, as it is a cross-border, cross-sectoral, and dynamic ecosystem. In such an ecosystem, the actors are represented by different countries, industries, research centers, and the distribution of roles between them varies depending on the life cycle of ongoing projects and the ecosystem as a whole. The ecosystem's pacemaker is the idea of developing fundamentally new technologies and materials in order to improve the quality of life.

Here are the subject areas of the ecosystem "Technologies for Improving the Quality of Life":

(1) Development of new methods for the diagnosis and separation of environmental technogenic nano-sized particles to reduce their impact on the safety and quality of human life.

(2) Technological reindustrialization to create the megalopolis of the future.

Here are the projects implemented by this ecosystem:

Project 1. Separation and Pre-Concentration in the Chemical Diagnostics of Functional Materials and Environmental Objects.

Project 2. Development and Prototyping of Engineering Solutions.

Project3. Mineral Mining and Waste Management.

Project 4. Artificial Intelligence and Technology for Robotics.

To implement each project, it is necessary to determine the composition of ecosystem actors. Several actors claim to play the role of individual actors (Table 4).

Table 4. Distribution of actor roles in the industrial ecosystem "Technologies for Improving the Quality of Life."

\begin{tabular}{|c|c|}
\hline Ecosystem Roles & Actors \\
\hline Initiator, customer & Ministry of Science and Higher Education of the Russian Federation \\
\hline Integrator & National University of Science and Technology (NUST) “MISiS” \\
\hline \multirow{3}{*}{ Developers } & $\begin{array}{l}\text { 1. Laboratory of Separation and Pre-Concentration in the Chemical Diagnostics of } \\
\text { Functional Materials and Environmental Objects at NUST "MISiS" }\end{array}$ \\
\hline & $\begin{array}{l}\text { 2. Vernadsky Institute of Geochemistry and Analytical Chemistry of the Russian } \\
\text { Academy of Sciences }\end{array}$ \\
\hline & $\begin{array}{l}\text { 3. Institute of Microelectronics Technology and High-Purity Materials Russian } \\
\text { Academy of Sciences }\end{array}$ \\
\hline \multirow{2}{*}{$\begin{array}{l}\text { Investment resource } \\
\text { providers }\end{array}$} & $\begin{array}{l}\text { 1. Support grants of Ministry of Science and Higher Education of the Russian } \\
\text { Federation }\end{array}$ \\
\hline & $\begin{array}{l}\text { 2. Russian enterprises of the nanotechnology industry (VIRIAL Ltd., CJSC R\&D } \\
\text { Micran, NEVZ-CERAMICS, JSC) }\end{array}$ \\
\hline \multirow{2}{*}{$\begin{array}{l}\text { Unique resource } \\
\text { providers }\end{array}$} & 1. Engineering Center for Industrial Prototyping of High-Complexity \\
\hline & 2. Industrial Technologies Engineering Center \\
\hline Project promoters & Center for Technology Commercialization at NUST "MISiS" \\
\hline \multirow{2}{*}{ Circularity generator } & 1. Center for Infrastructure Cooperation and Partnership MegaScience \\
\hline & 2. Brunel University \\
\hline
\end{tabular}

The developers play a key role in the development of new technologies and materials. The attractiveness of three developers for the ecosystem in terms of cooperation with other actors was evaluated based on the method of analytic hierarchy process via integral indicators. Developer 1 is the Laboratory at NUST "MISiS" (D1); Developer 2 is the Vernadsky Institute of Geochemistry and Analytical Chemistry of the Russian Academy of Sciences (D2); Developer 3 is the Institute of Microelectronics Technology and High-Purity Materials Russian Academy of Sciences (D3). The rest of the ecosystem actors acted as experts and evaluated three participants claiming to be a Developer in the ecosystem "Technologies for Improving the Quality of Life" (Table 5). The importance of indicators in each of the five blocks for developers was determined by experts on a scale from 0 to 5 . 
Table 5. Results of cross-validation of candidates for the role of "Developer" in the ecosystem.

\begin{tabular}{|c|c|c|c|c|c|}
\hline \multirow{2}{*}{ No. } & \multirow{2}{*}{$\begin{array}{l}\text { Integrated } \\
\text { Indicator }\end{array}$} & \multirow{2}{*}{ Criteria } & \multicolumn{3}{|c|}{ Expert Review } \\
\hline & & & $\mathrm{D}_{1}$ & $\mathbf{D}_{2}$ & $\mathrm{D}_{3}$ \\
\hline \multirow{5}{*}{$\mathrm{B}_{1}$} & \multirow{5}{*}{$\begin{array}{l}\text { Technological } \\
\text { potential }(T)\end{array}$} & C1.1 technological processes efficiency level & 3 & 4 & 4 \\
\hline & & C1.2 resource intensity of production & 5 & 4 & 3 \\
\hline & & C1.3 product quality & 4 & 5 & 5 \\
\hline & & C1.4 level of automation and digitalization of production & 5 & 4 & 4 \\
\hline & & C1.5 share of unique technologies in the overall structure & 3 & 3 & 2 \\
\hline \multirow{5}{*}{$\mathrm{B}_{2}$} & \multirow{5}{*}{$\begin{array}{l}\text { Environmental } \\
\text { friendliness }(E)\end{array}$} & $\begin{array}{l}\text { C2.1 level of implementation of modern resource-saving "smart" } \\
\text { technologies }\end{array}$ & 3 & 4 & 4 \\
\hline & & C2.2 amount of financing of environmental protection & 2 & 3 & 3 \\
\hline & & C2.3 amount of industrial and solid waste & 3 & 5 & 4 \\
\hline & & C2.4 level of water, air, and soil pollution & 4 & 3 & 4 \\
\hline & & C2.5 availability of educational environmental programs and projects & 5 & 3 & 4 \\
\hline \multirow{5}{*}{$\mathrm{B}_{3}$} & \multirow{5}{*}{$\begin{array}{c}\text { Social } \\
\text { environment } \\
(S)\end{array}$} & C3.1 level of social spending and investment in human capital & 5 & 5 & 4 \\
\hline & & C3.2 the number of accidents in the company per 1000 employees & 5 & 3 & 4 \\
\hline & & C3.3 degree of employee satisfaction with environmental quality & 4 & 3 & 3 \\
\hline & & C 3.4 corporate culture level & 4 & 3 & 4 \\
\hline & & C3.5 long-term relationships with partners and consumers & 5 & 5 & 3 \\
\hline \multirow{5}{*}{$\mathrm{B}_{4}$} & \multirow{5}{*}{$\begin{array}{l}\text { Innovation } \\
\text { potential }(I)\end{array}$} & C4.1 innovativeness level & 5 & 4 & 5 \\
\hline & & $\begin{array}{l}\text { C4.2 investment resource endowment for financing innovative } \\
\text { programs and projects }\end{array}$ & 4 & 4 & 3 \\
\hline & & C4.3 level of personnel qualification and intellectual potential & 5 & 5 & 5 \\
\hline & & C4.4 viability of innovations & 4 & 5 & 4 \\
\hline & & C4.5 innovative competence & 5 & 4 & 4 \\
\hline \multirow{5}{*}{$\mathrm{B}_{5}$} & \multirow{5}{*}{$\begin{array}{l}\text { Management } \\
\text { maturity }(M)\end{array}$} & C5.1 level of infrastructure development & 5 & 4 & 4 \\
\hline & & C5.2 business reputation & 4 & 3 & 4 \\
\hline & & C5.3 resource provision & 4 & 4 & 3 \\
\hline & & $\begin{array}{l}\text { C } 5.4 \text { balancing the exchange of knowledge and resources between } \\
\text { actors }\end{array}$ & 4 & 3 & 4 \\
\hline & & C5.5 level of self-organization & 3 & 3 & 3 \\
\hline
\end{tabular}

The first step in accordance with the AHP method is to construct a hierarchical structure combining the goal, criteria, alternatives, and other factors that influence the choice of decision (Figure 4).

The next step is to conduct a pairwise comparison of the importance of five blocks of indicators for each potential actor for the role of a developer. The comparison results are shown in Table 6.

Table 6. Evaluation matrix of importance of indicator blocks for developer.

\begin{tabular}{cccccc}
\hline & B1 & B2 & B3 & B4 & B5 \\
\hline B1 & 1 & 5 & $1 / 5$ & $1 / 5$ & 1 \\
\hline B2 & $1 / 5$ & 1 & $1 / 9$ & $1 / 9$ & $1 / 5$ \\
\hline B3 & 5 & 9 & 1 & 1 & 5 \\
\hline B4 & 5 & 9 & 1 & 1 & 5 \\
\hline B5 & 1 & 5 & $1 / 5$ & $1 / 5$ & 1 \\
\hline$\Sigma$ & 12,200 & 29,000 & 2.511 & 2.511 & 12,200 \\
\hline
\end{tabular}

Then, it is necessary to define the normalized priority vector (NVP): 
(a) calculate the geometric mean in each row of the matrix by Equation (1):

$$
\begin{gathered}
a_{1}=\sqrt[5]{1 \times 5 \times(1 / 5) \times(1 / 5) \times 1}=0.725 \\
a_{2}=\sqrt[5]{(1 / 5) \times 1 \times(1 / 9) \times(1 / 9) \times 1 \times(1 / 5)}=0.218
\end{gathered}
$$

Similarly:

$$
a_{3}=2.954 ; a_{4}=2.954 ; a_{5}=0.725
$$

(b) calculate the sum of geometric mean by Equation (2):

$$
S=0.725+0.218+2.954+2.954+0.725=7.576
$$

(c) using Equation (3), calculate the NVP components for the developer:

$$
\begin{aligned}
& N V P_{1}=\frac{0.725}{7.576}=0.095 \\
& N V P_{2}=\frac{0.218}{7.576}=0.028 \\
& N V P_{3}=\frac{2.954}{7.576}=0.390 \\
& N V P_{4}=\frac{2.954}{7.576}=0.390 \\
& N V P_{5}=\frac{0.725}{7.576}=0.096
\end{aligned}
$$

Then, the consistency of evaluations in the matrix should be checked. The eigenvalue of the matrix Equation (4) is as follows:

(a)

$$
\lambda_{\max }=0.096 \times 12.2+0.028 \times 29+0.390 \times 2.511+0.390 \times 2.511+0.096 \times 12.2=5.1276
$$

(b) the consistency index Equation (5) is:

$$
C I=\frac{5.1276-5}{5-1}=0.0319
$$

(c) as the random consistency index for criteria 5 is 1.12 in accordance with Table 5, the consistency ratio Equation (6) is:

$$
C R=\frac{0.0319}{1.12}=0.0285
$$

Since the consistency ratio is $2.85 \%$, the evaluations of blocks in the matrix can be considered consistent, and the resulting priority vector can be used as weight coefficients of importance of each block during the selection procedure. The results of calculating the priorities of blocks are shown in Table 7.

Table 7. Priority vectors of blocks for the developer.

\begin{tabular}{cc}
\hline Block & NVP for the Developer \\
\hline Technological potential & 0.104 \\
\hline Environmental friendliness & 0.045 \\
\hline Social environment & 0.104 \\
\hline Innovation potential & 0.246 \\
\hline Management maturity & 0.501 \\
\hline
\end{tabular}


A similar comparison procedure is carried out for each group of indicators within the blocks for a potential actor. The final procedure for calculating criteria priorities is carried out by multiplying the priorities of indicators by the priorities of the corresponding blocks. The resulting vectors of criteria indicators for the developer are shown in Table 8 (designations for Figure 5 are used in the Table).

Table 8. The resulting vectors of criteria priority for the developer.

\begin{tabular}{|c|c|c|c|c|c|c|c|c|}
\hline \multirow{2}{*}{ Block } & \multirow{2}{*}{ Criteria } & \multirow{2}{*}{$\begin{array}{l}\text { NVP of the } \\
\text { Developer }\end{array}$} & \multicolumn{3}{|c|}{$\begin{array}{l}\text { Particular Criterion } \\
\text { Priority, }\left(\alpha_{j}\right)\end{array}$} & \multicolumn{3}{|c|}{$\begin{array}{l}\text { General Criterion for an } \\
\text { Alternative, } C(x)\end{array}$} \\
\hline & & & $D_{1}$ & $\mathrm{D}_{2}$ & $\mathrm{D}_{3}$ & $\mathrm{D}_{1}$ & $\mathrm{D}_{2}$ & $\mathrm{D}_{3}$ \\
\hline \multirow{5}{*}{ B1 } & C1.1 & 0.006125 & 3 & 4 & 4 & 0.018375 & 0.0245 & 0.0245 \\
\hline & C1.2 & 0.034446 & 5 & 4 & 3 & 0.17223 & 0.137784 & 0.103338 \\
\hline & C1.3 & 0.014525 & 4 & 5 & 5 & 0.058101 & 0.072627 & 0.072627 \\
\hline & C1.4 & 0.034446 & 5 & 4 & 4 & 0.17223 & 1.440237 & 0.137784 \\
\hline & C1.5 & 0.006125 & 3 & 3 & 2 & 0.018375 & 0.018375 & 0.01225 \\
\hline \multicolumn{2}{|c|}{$\begin{array}{l}\text { Final evaluation for } \\
\text { Block } 1\end{array}$} & & & & & 0.439311 & 0.391069 & 0.350498 \\
\hline \multirow{5}{*}{ B2 } & $\mathrm{C} 2.1$ & 0.002988 & 3 & 4 & 4 & 0.008963 & 0.011951 & 0.011951 \\
\hline & $\mathrm{C} 2.2$ & 0.001305 & 2 & 3 & 3 & 0.002609 & 0.003914 & 0.003914 \\
\hline & $\mathrm{C} 2.3$ & 0.002988 & 3 & 5 & 4 & 0.008963 & 0.014939 & 0.011951 \\
\hline & $\mathrm{C} 2.4$ & 0.007085 & 4 & 3 & 4 & 0.028341 & 0.021256 & 0.028341 \\
\hline & $\mathrm{C} 2.5$ & 0.014427 & 5 & 3 & 4 & 0.072134 & 0.04328 & 0.057707 \\
\hline \multicolumn{2}{|c|}{$\begin{array}{l}\text { Final evaluation for } \\
\text { Block } 2\end{array}$} & & & & & 0.12101 & 0.095339 & 0.113864 \\
\hline \multirow{5}{*}{ B3 } & C3.1 & 0.106346 & 5 & 5 & 4 & 0.531732 & 0.531732 & 0.425385 \\
\hline & C 3.2 & 0.106346 & 5 & 3 & 4 & 0.531732 & 0.319039 & 0.425385 \\
\hline & C 3.3 & 0.035449 & 4 & 3 & 3 & 0.141795 & 0.106346 & 0.106346 \\
\hline & C 3.4 & 0.035449 & 4 & 3 & 4 & 0.141795 & 0.106346 & 0.141795 \\
\hline & C 3.5 & 0.106346 & 5 & 5 & 3 & 0.531732 & 0.531732 & 0.319039 \\
\hline \multicolumn{2}{|c|}{$\begin{array}{l}\text { Final evaluation for } \\
\text { Block } 3\end{array}$} & & & & & 1.878786 & 1.595195 & 1.417952 \\
\hline \multirow{5}{*}{ B4 } & $\mathrm{C} 4.1$ & 0.106346 & 5 & 4 & 5 & 0.531732 & 0.425385 & 0.531732 \\
\hline & $\mathrm{C} 4.2$ & 0.035449 & 4 & 4 & 3 & 0.141795 & 0.141795 & 0.106346 \\
\hline & C4.3 & 0.106346 & 5 & 5 & 5 & 0.531732 & 0.531732 & 0.531732 \\
\hline & C4.4 & 0.035449 & 4 & 5 & 4 & 0.141795 & 0.177244 & 0.141795 \\
\hline & C4.5 & 0.106346 & 5 & 4 & 4 & 0.531732 & 0.425385 & 0.425385 \\
\hline \multicolumn{2}{|c|}{$\begin{array}{l}\text { Final evaluation for } \\
\text { Block } 4\end{array}$} & & & & & 1.878786 & 1.701542 & 1.736991 \\
\hline \multirow{5}{*}{ B5 } & C5.1 & 0.042231 & 5 & 4 & 4 & 0.211157 & 0.168926 & 0.168926 \\
\hline & C5.2 & 0.015833 & 4 & 3 & 4 & 0.063333 & 0.0475 & 0.063333 \\
\hline & C5.3 & 0.015833 & 4 & 4 & 3 & 0.063333 & 0.063333 & 0.0475 \\
\hline & C5.4 & 0.015833 & 4 & 3 & 4 & 0.063333 & 0.0475 & 0.063333 \\
\hline & C5.5 & 0.005936 & 3 & 3 & 3 & 0.017808 & 0.017808 & 0.017808 \\
\hline \multicolumn{2}{|c|}{$\begin{array}{l}\text { Final evaluation for } \\
\text { Block } 5\end{array}$} & & & & & 0.418965 & 0.345067 & 0.3609 \\
\hline \multicolumn{2}{|c|}{ Integral evaluation: } & & & & & 4.736857 & 4.128213 & 3.9802043 \\
\hline
\end{tabular}

Based on expert evaluations, scores are distributed for participants on a unified scale for each of the listed indicators. The participant's final evaluation is calculated using the additive convolution Equation (7). In accordance with the AHP method, the higher the integral estimate of an actor, the more it is suitable for the intended role. 
In terms of meeting the ecosystem goals, the most significant criteria are management maturity and innovation potential. The values of these criteria are 0.419 and 1.879 for Developer 1, 0.345 and 1.702 for Developer 2, and 1.737 and 0.361 for Developer 3. Accordingly, Developer 2 holds the second position in terms of ecosystem attractiveness with final integral evaluation of 4.128. Although, according to the final evaluation for two key blocks, the scores for Developer 3 are higher.

From the point of view of sustainable development, Developer 1 has the best result with the total value of 2.419 for three blocks (ESG), the score of Developer 2 is 2.036, and it is 1.893 for Developer 3. When analyzing the results of the assessment, Developer 1 holds the first place with a value of 2.318, Developer 2 is the second with 2.093, and Developer 3 is the third with potentials value of 2.087.

For all five blocks of indicators, D1-the Laboratory of Separation and Pre-Concentration in the Chemical Diagnostics of Functional Materials and Environmental Objects at NUST "MISiS"-is the most significant (attractive) one for the ecosystem "Technologies for Improving the Quality of Life." Its integral evaluation, showing suitability of the analyzed participant for the intended role in the project, was 4.7368, which is 0.64 points higher than the closest competitor, Developer 2.

\section{Discussion}

Thus, by accumulating positive points through cross-validation, the actor becomes attractive in terms of cooperation in joint projects for other participants. With the help of a cross-validation tool, an actor can directly influence other actors through their own validation, further making a well-grounded independent decision on cooperation in each individual project. To ensure the functioning of the ecosystem self-adjusting, the assessment should be carried out constantly, both at the entrance of the actor into the ecosystem and after the implementation of each project. The goal of this approach is to create an ecosystem platform that allows actors to effectively interact within the ecosystem, respond flexibly to challenges, stay ahead of negative phenomena, and adjust their strategies. This will ultimately make it possible to ensure the sustainable development of each actor and the ecosystem as a whole.

Considering the open innovation paradigm, it is obvious that, at the micro level, open innovation is an advantage for any company, regardless of size and industry, and a driver in the context of globalized economic activity. From a macro-economic point of view, the following question arises. Do the open innovations contribute to turning innovation-based growth into a benefit for all participants in the context of regional policy? The authors studied this problem on the example of two regions [8].

The quadruple innovation helix model connects social ecology, knowledge, and innovation. The most important system-forming element is the knowledge resource, which, as a result of the circulation of knowledge, turns into innovations and know-how implemented in society and the economy. This raises another question in open innovation: the level of spillover effects in global value chains. Spillover effects are characterized by complex multi-factor flows of knowledge between manufacturers of equipment, products, technologies, and knowledge in ecosystems, and their dependence on the institutional features of the territories where ecosystems arise.

Definitely, the innovation ecosystem concept and its contribution to the scientific literature on innovation and industrial processes cannot be fully understood without a self-organization and sustainability perspective [65-68]. Meanwhile, such issue as what mechanisms form an innovation ecosystem in a sustainable and self-organizing way is underexplored in the academic literature. In the article, the authors propose a practical tool for assessing an ecosystem's actor using the method of analytic hierarchy process (AHP). This method is relevant for group decision-making, and is aimed primarily at solving practice-oriented problems of multicriteria optimization. Among the main advantages of this method is the ability to take into account a large number of both quantitative and qualitative criteria for optimality. Its ease and versatility of using has served as the basis for mass application in solving problems of optimal resource allocation according to established priorities among many alternatives in business and management [69], quality management [70], ecology [71], 
programming [72], education [73], oil industry [74], construction [75], nuclear energy [76], transport [77], and other fields.

Meanwhile, the proposed practical tool has some limitations in practical use. The following main limitations should be mentioned: labor-intensive approach, high volatility of estimates, and high susceptibility to the ranking method and parameter values.

The evaluation algorithm using the proposed method can be improved in the following ways:

(1) For some actors, the implementation of certain criteria is optional (non-essential). In this case, it is proposed to modify the method of pairwise comparisons as follows: if the significance of any criterion for the actor is " 0, " then in the matrix of pairwise comparisons for all other criteria a relatively large number is set (for example, "100"), respectively, the relative importance of the criteria will be close to " 0 " (0.01).

(2) Considering a rather large number of criteria (" $\left.25^{\prime \prime}\right)$, as well as the possibility of further increasing their number, when performing additive convolution it is possible to limit the number of included criteria by setting a lower threshold for their significance (for example, " 0.05 ").

The authors raise the following questions to be addressed as future perspectives for the research. Future works on innovation ecosystems would focus on ecosystem platforms' development issue, which make it possible to model and capture the self-organization and self-development mechanisms of innovation ecosystems. Culture for open innovation dynamics is also important in the realization of self-development mechanisms, because the actors have to conquer cultural barriers in addition to legal and institutional barriers. Enhancing the culture of collaboration in innovation ecosystems will allow actors to work effectively both within the system and more actively cooperate with external parties. Accumulated cross-validation data will become the basis for the formation of a unified ecosystem data bank, and in the future, a project office can be created thereon based on a blockchain and a digital platform, ensuring the interconnection between actors in the ecosystem.

\section{Conclusions}

This paper proposed a methodological framework for studying innovation ecosystems in the context of self-organization and sustainability perspective. The main research question was how to operationalize the processes of self-organization in the innovation ecosystem without an external governing body. To this end, the authors propose a new tool for cross-validation of an ecosystem's actors based on the method of analytic hierarchy process (AHP). It allows for operationalizing the processes of self-organization in the ecosystem without an external intervention and addresses the main implications for sustainable development of innovation industrial ecosystems.

The authors illustrated their assumptions with an empirical case study of the industrial ecosystem "Technologies for Improving the Quality of Life," which is part of the ecosystem of the National University of Science and Technology (NUST) "MISiS" (Moscow, Russia).

The propositions arising from this analysis provide information to help academics, policymakers, government, and individual enterprises with a more adequate understanding of the practical mechanisms and tools that help trigger self-organization and sustainable development of the innovation ecosystems.

The proposed novel tool for assessing an actor of the ecosystem makes a significant contribution to the innovation ecosystem theory and methodology development in terms of conceptualization of the self-organization and self-development processes and further investigation of their impact on ecosystem sustainable development.

Author Contributions: Conceptualization, methodology, formal analysis, supervision, T.T.: conceptualization, elaborated the literature review, supervision, data validation, writing-original draft preparation, L.G.; writing-original draft preparation, collected data, data validation, performed the first data analyses, N.S. All authors have read and agreed to the published version of the manuscript. 
Funding: This research was funded by RFBR grant No. 20-010-00470. The results of Section 5 were obtained within the RSF grant (project No. 20-71-10087). Data for publication were collected with the financial support of the project of grant funding for young scientists for the implementation of research on scientific and (or) technical projects, AP08053346 "Research of sustainable development innovations from the perspective of their economic feasibility and building effective enterprise management in the Republic of Kazakhstan."

Conflicts of Interest: The authors declare no conflict of interest.

\section{References}

1. Transforming Our World: The 2030 Agenda for Sustainable Development. Available online: https: //sustainabledevelopment.un.org/post2015/transformingourworld (accessed on 12 September 2020).

2. WCED. Report of the World Commission on Environment and Development: Our Common Future. United Nations. 1987. Available online: http://www.un-documents.net/our-common-future.pdf (accessed on 16 July 2020).

3. Zu, L. Sustainable Enterprise Development. In Encyclopedia of Corporate Social Responsibility; Idowu, S.O., Capaldi, N., Zu, L., Gupta, A.D., Eds.; Springer: Berlin/Heidelberg, Germany, 2013. [CrossRef]

4. Hope, J. Making the transition to the sustainable enterprise economy. J. Corp. Citiz. 2009, 34, 35-40.

5. Wirtenberg, J.; Russell, G.; Lipsky, D. The Sustainable Enterprise Fieldbook; Greenleaf Publishing: Sheffield, UK, 2008.

6. Skorobogatova, N. Sustainable Development of an Enterprise under Industry 4.0 Conditions. In Proceedings of the 2019 International Conference on Creative Business for Smart and Sustainable Growth (CREBUS), Sandanski, Bulgaria, 18-21 March 2019; pp. 1-5. [CrossRef]

7. Tolstykh, T.; Shmeleva, N.; Gamidullaeva, L. Evaluation of Circular and Integration Potentials of Innovation Ecosystems for Industrial Sustainability. Sustainability 2020, 12, 4574. [CrossRef]

8. Tolstykh, T.; Shmeleva, N.; Gamidullaeva, L.; Lapygin, Y. Regional Development in Russia: An Ecosystem Approach to Territorial Sustainability Assessment. Sustainability 2020, 12, 6424. [CrossRef]

9. Shmeleva, N. The new business model for circular economy: Moving from theory to practice. In Proceedings of the 18th International multidisciplinary scientific GEO conference SGEM 2018, Albena, Bulgaria, 2-8 July 2018; Volume 18, pp. 919-926.

10. Taleb, N.N. Antifragile: Things That Gain from Disorder; KoLibri, Azbuka-Attikus: Moscow, Russia, 2014.

11. Yun, J.J.; Liu, Z. Micro- and Macro-Dynamics of Open Innovation with a Quadruple-Helix Model. Sustainability 2019, 11, 3301. [CrossRef]

12. Yun, J.J.; Zhao, X.; Jung, K.; Yigitcanlar, T. The Culture for Open Innovation Dynamics. Sustainability 2020, 12, 5076. [CrossRef]

13. Ma, L.; Liu, Z.; Huang, X.; Li, T. The Impact of Local Government Policy on Innovation Ecosystem in Knowledge Resource Scarce Region: Case Study of Changzhou, China. Sci. Technol. Soc. 2019, 24, $29-52$. [CrossRef]

14. Yun, J.J.; Won, D.; Park, K. Entrepreneurial cyclical dynamics of open innovation. J. Evol. Econ. 2018, 28, 1151-1174. [CrossRef]

15. Jean, G.; Dirk, M. Open Innovation: Effects for Corporate Strategies, Public Policy, and International R\&D "Flow". Foresight. 2012. Available online: https://cyberleninka.ru/article/n/otkrytye-innovatsii-effekty-dlyakorporativnyh-strategiy-gosudarstvennoy-politiki-i-mezhdunarodnogo-peretoka-issledovaniy-i (accessed on 21 September 2020).

16. Guinet, J.; Meissner, D. Open Innovation: Implications for Corporate Strategies, Government Policy and International R\&D Spillovers. Foresight STI Gov. 2012, 6, 26-36.

17. Carayannis, E.; Grigoroudis, E. Quadruple Innovation Helix and Smart Specialization: Knowledge Production and National Competitiveness. Foresight STI Gov. 2016, 10, 31-42. [CrossRef]

18. Carayannis, E.G.; Barth, T.D.; Campbell, D.F. The Quintuple Helix innovation model: Global warming as a challenge and driver for innovation. J. Innov. Entrep. 2012, 1, 2. [CrossRef]

19. Tansley, A.G. The use and abuse of vegetational concepts and terms. Ecology 1935, 16, 284-307. [CrossRef]

20. Jacobides, M.G.; Cennamo, C.; Gawer, A. Towards a theory of ecosystems. Strateg. Manag. J. 2018, 39, 2255-2276. [CrossRef]

21. Moore, J.F. The Death of Competition: LEADERSHIP and Strategy in the Age of Business Ecosystems; HarperCollins: New York, NY, USA, 1996; p. 297. 
22. Adner, R.; Kapoor, R. Value creation in innovation ecosystems: How the structure of technological interdependence affects firm performance in new technology generations. Strateg. Manag. J. 2010, 31, 306-333. [CrossRef]

23. Autio, E.; Thomas, L. Innovation Ecosystems. In The Oxford Handbook of Innovation Management; Oxford University Press: Oxford, UK, 2014; pp. 204-288. Available online: https://www.rvc.ru/upload/iblock/06b/ Innovation_ecosystem_analytical_report.pdf (accessed on 12 September 2020).

24. Kleiner, G.B. Ecosystem economy: Step into the future. Econ. Rev. Russ. 2019, 1, 40-45.

25. Proskurnin, S.D. Creation of self-organized innovative ecosystems in zones of special territorial development. Reg. Econ. Manag. Electron. Sci. J. 2017, 4, 5206. Available online: https://eee-region.ru/article/5206/ (accessed on 12 September 2020).

26. Granstrand, O.; Holgersson, M. Innovation ecosystems: A conceptual review and a new definition. Technovation 2020, 90. [CrossRef]

27. Gamidullaeva, L.A.; Tolstykh, T.O.; Shmeleva, N.V. Methodology for a comprehensive assessment of the potential of an industrial ecosystem in the context of sustainable development of the region. Models Syst. Netw. Econ. Technol. Nat. Soc. 2020, 2, 29-49.

28. Chesbrough, H.W.; Vanhaverbeke, W.; West, J. Open Innovation: Researching A New Paradigm; Oxford University Press: Oxford, UK, 2006.

29. Barney, J.B.; Hesterly, W.S. Strategic Management and Competitive Advantage: Concepts and Cases, 5th ed.; Prentice Hall: Upper Saddle River, NJ, USA, 2010.

30. Porter, M.E. Competitive Advantage: Creating and Sustaining Superior Performance; Free Press: New York, NY, USA, 1985.

31. Teece, D.J. Profiting from technological innovation: Implications for integration, collaboration, licensing and public policy. Res. Policy 1986, 15, 285-305. [CrossRef]

32. Jones, G.R. Organizational Theory, Design, and Change; Pearson: Upper Saddle River, NJ, USA, 2013.

33. Powell, W.W.; Koput, K.W.; Smith-Doerr, L. Interorganizational collaboration and the locus of innovation: Networks of learning in biotechnology. Adm. Sci. Q. 1996, 41, 116-145. [CrossRef]

34. Nelson, R.; Winter, S.G. An Evolutionary Theory of Economic Change; Belknap Press/Harvard University Press: Cambridge, MA, USA, 1982.

35. Ayres, R.U.; Ayres, L.A. Handbook of Industrial Ecology; Edward Elgar Publishing: Cheltenham, UK, 2002.

36. Tsujimoto, M.; Kajikawa, Y.; Tomita, J.; Matsumoto, Y. A review of the ecosystem concept-Towards coherent ecosystem design. Technol. Forecast. Soc. Chang. 2018, 136, 49-58. [CrossRef]

37. Autio, E.; Thomas, L. Ecosystem Value Co-Creation. In Innovation E Entrepreneurship Department Working Papers; Imperial College Business School: London, UK, 2016.

38. Lusch, R.F.; Nambisan, S. Service innovation: A service-dominant logic perspective. MIS 2015, 39, $155-175$. [CrossRef]

39. Lodhia, S.; Jacobs, K. The practice turn in environmental reporting. Account. Audit. Account. J. 2013, 26, 595-615. [CrossRef]

40. Elkington, J. Towards the sustainable corporation: Win-win-win business strategies for sustainable development. Calif. Manag. Rev. 1994, 36, 90-100. [CrossRef]

41. Riccaboni, A.; Luisa Leone, E. Implementing strategies through management control systems: The case of sustainability. Int. J. Product. Performan. Manag. 2010, 59, 130-144. [CrossRef]

42. Venturelli, A.; Luison, C.; Badalotti, G.; Bodo, R.; Caputo, F.; Corvino, A.; Minoja, M. The SDGs in the Reports of the Italian Companies; Assirevi: Milano, Italy, 2019.

43. Caputo, F.; Veltri, S.; Venturelli, A. A conceptual model of forces driving the introduction of a sustainability report in SMEs: Evidence from a case study. Int. Bus. Res. 2017, 10, 39-50. [CrossRef]

44. Feder, M.; Weißenberger, B.E. Understanding the behavioral gap: Why would managers (not) engage in CSR-related activities? J. Manag. Control 2019, 30, 95-126. [CrossRef]

45. Johnson, M.; Schaltegger, S. Sustainable Entrepreneurship as a Research Field? Evidence from a Systematic Literature Review. Acad. Manag. Proc. 2016, 16175. [CrossRef]

46. Teece, D.J. Explicating dynamic capabilities: The nature and microfoundations of (sustainable) enterprise performance. Strateg. Manag. J. 2007, 28, 1319-1350. [CrossRef]

47. Castiaux, A. Developing dynamic capabilities to meet sustainable development challenges. Int. J. Innov. Manag. 2012, 16, 124-140. [CrossRef] 
48. Wu, Q.; He, Q.; Duan, Y.; O’Regan, N. Implementing dynamic capabilities for corporate strategic change toward sustainability. Strateg. Manag. J. 2012, 21, 231-247. [CrossRef]

49. Saaty, T.L.; Luis, G. Vargas the Logic of Priorities: Applications in Business, Energy, Health, and Transportation; Kluwer-Nijhoff: Boston, MA, USA, 1982.

50. Saaty, T. An Eigenvalue Allocation Model for Prioritization and Planning. In Working Paper, Energy Management and Policy Center; University of Pennsylvania: Philadelphia, PA, USA, 1972.

51. Saaty, T. A scaling method for priorities in hierarchical structures. J. Math. Psychol. 1977, 15, $234-281$. [CrossRef]

52. Lyu, H.M.; Zhou, W.H.; Shen, S.L.; Zhou, A. Inundation risk assessment of metro system using AHP and TFN-AHP in Shenzhen. Sustain. Cities Soc. 2020, 56, 102103. [CrossRef]

53. Bathrinath, S.; Bhalaji, R.K.A.; Saravanasankar, S. Risk analysis in textile industries using AHP-TOPSIS. Mater. Today Proc. 2020, in press. [CrossRef]

54. Kokangül, A.; Polat, U.; Dağsuyu, C. A new approximation for risk assessment using the AHP and Fine Kinney methodologies. Saf. Sci. 2017, 91, 24-32. [CrossRef]

55. Zhang, Y.; Sun, Y.; Qin, J. Sustainable development of coal cities in Heilongjiang province based on AHP method. Int. J. Min. Sci. Technol. 2012, 22, 133-137. [CrossRef]

56. Gupta, P.; Mehlawat, M.K.; Aggarwal, U.; Charles, V. An integrated AHP-DEA multi-objective optimization model for sustainable transportation in mining industry. Resour. Policy 2018. [CrossRef]

57. Javadian, M.; Shamskooshki, H. Application of Sustainable Urban Development in Environmental Suitability Analysis of Educational Land Use by Using Ahp and Gis in Tehran. Procedia Eng. 2011, 21, 72-80. [CrossRef]

58. Shen, L.; Muduli, K.; Barve, A. Developing a sustainable development framework in the context of mining industries: AHP approach. Resour. Policy 2015, 46, 15-26. [CrossRef]

59. $\mathrm{Xu}, \mathrm{S} . ; \mathrm{Xu}, \mathrm{D}$. Construction of regional informatization ecological environment based on the entropy weight modified AHP hierarchy model. Sustain. Comput. Inform. Syst. 2019, 22, 26-31. [CrossRef]

60. Zhang, R.; Yang, J. Wetland ecosystem stability evaluation by using Analytical Hierarchy Process (AHP) approach in Yinchuan Plain, China. Math. Comput. Model. 2013, 57, 366-374. [CrossRef]

61. Sun, B.; Tang, J. Ecosystem health assessment: A PSR analysis combining AHP and FCE methods for Jiaozhou Bay, China. Ocean Coast. Manag. 2019, 1681, 41-50. [CrossRef]

62. Shvab, K. The Fourth Industrial Revolution. 2016. Moscow. Available online: https://www.vedomosti.ru/ economics/articles/2020/01/14/820569-davosskii-forum-manifest-biznesa (accessed on 12 June 2020).

63. Expert RA Rating Agency. Available online: https://raexpert.ru/ (accessed on 12 June 2020).

64. HSE Data Books. Available online: https://www.hse.ru/primarydata/ (accessed on 12 June 2020).

65. Liu, Z.; Stephens, V. Exploring Innovation Ecosystem from the Perspective of Sustainability: Towards a Conceptual Framework. J. Open Innov. Technol. Mark. Complex 2019, 5, 48. [CrossRef]

66. Basole, R.C. Visualization of interfirm relations in a converging mobile ecosystem. J. Inf. Technol. 2009, 24, 144-159. [CrossRef]

67. Peltoniemi, M. Preliminary theoretical framework for the study of business ecosystems. Emerg. Complex. Organ. 2006, 8, 10-19.

68. Lenort, R.; Zapletal, F.; Wicher, P.; Shmeleva, N. Sustainability Development Goals Preferences in Metallurgical and Mining Industry. In Proceedings of the 29 International Conference in Metallurgy and Materials-METAL 2020, Brno, Czech Republic, 19-21 May 2020; pp. 1237-1248.

69. Vargas, L.; Saaty, T. Models, Methods, Concepts \& Applications of the Analytic Hierarchy Process; Kluwer Academic: Boston, MA, USA, 2001.

70. Ayhan, M.B. Fuzzy AHP Approach for supplier selection problem: A case study in a gearmotor company. Int. J. Manag. Value Supply Chain. 2013, 4. [CrossRef]

71. Berrittella, M.; Certa, A.; Enea, M.; Zito, P. An Analytic Hierarchy Process for the Evaluation of Transport Policies to Reduce Climate Change Impacts; Working Papers 2007.12; Fondazione Eni Enrico Mattei: Milan, Italy, 2007.

72. McCaffrey, J. Test Run: The Analytic Hierarchy Process. MSDN Magazine. 2005. Available online: https://docs. microsoft.com/en-us/archive/msdn-magazine/2005/june/test-run-the-analytic-hierarchy-process (accessed on 16 July 2020).

73. Grandzol, J.R. Improving the Faculty Selection Process in Higher Education: A Case for the Analytic Hierarchy Process. IR Appl. Using Adv. Tools Tech. Methodol. 2005, 6, 2-12. 
74. Dey, P.K. Analytic Hierarchy Process Analyzes Risk of Operating Cross-Country Petroleum Pipelines in India. Nat. Hazards Rev. 2003, 4, 213-221. [CrossRef]

75. Salem, O.; Salman, B.; Ghorai, S. Accelerating construction of roadway bridges using alternative techniques and procurement methods. Transport 2017, 33, 567-579. [CrossRef]

76. Locatelli, G.; Mancini, M. A framework for the selection of the right nuclear power plant. Int. J. Prod. Res. 2012, 50, 4753-4766. [CrossRef]

77. Salavati, A.; Haghshenas, H.; Ghadirifaraz, B.; Laghaei, J.; Eftekhari, G. Applying AHP and Clustering Approaches for Public Transportation Decisionmaking: A Case Study of Isfahan City. J. Public Transp. 2016, 19, 3. [CrossRef]

(C) 2020 by the authors. Licensee MDPI, Basel, Switzerland. This article is an open access article distributed under the terms and conditions of the Creative Commons Attribution (CC BY) license (http://creativecommons.org/licenses/by/4.0/). 